\title{
Research Progress of Leadership from the Perspective of Partnership and Followership
}

\author{
Wenxin Guo ${ }^{1}$ and Yuxin Yan ${ }^{1, *}$ \\ ${ }^{1}$ School of Government, Beijing Normal University, Beijing 100875, China \\ *Corresponding author. Email:201821260031@mail.bnu.edu.cn
}

\begin{abstract}
In the process of the survival and development of the organization, the leader is always at the core. The leader is related to the survival and development of the organization, so the leadership ability determines the future of the enterprise. This article summarizes the current status of leadership research, traces the existing literature on the definition of leadership and related research on leadership development, and combines the rise of followership research in recent years to construct a cooperation model from the perspective of followership and leadership, proposed that in the process of cooperation, the leader and the follower are equal and have the same value, and leadership should dynamically exist between the leader and the follower. Finally, this article discusses and proposes five methods to improve leadership from the perspective of cooperation and followership, including improving the decision-making framework, conducting performance training, providing organizational guidance, flatting management model, and building a relationship framework. The analysis and exploration of this article aims to provide a reference for the development direction and research path of followership research in the future.

Keywords: leadership; followership; partnership; leadership development
\end{abstract}

\section{INTRODUCTION}

With the continuous deepening of economic system reforms and the ever-changing market competition environment, the uncertainty of organizational development has increased significantly. In this context, on the one hand, it is difficult to adapt to the economic development requirements of the new era by relying solely on the concept of leadership as the core to lead the development of the enterprise. On the other hand, it is particularly important to enhance the initiative of employees, stimulate their followership, and improve organizational efficiency and environmental adaptability in the interaction between leaders and employees. In view of this, with the current dynamic competitive environment, knowledge-led corporate environment and changes in the main body of employees, it is of practical significance to explore the issue of followership.

Followership is the foundation of the leadership process. Leadership is accomplished through followers. Without followership, the positive impact of leadership on the organization cannot be realized. It can be seen that followership has become an indispensable part of the development of organizational leadership, and it is the frontier and hot topic of current leadership research.

In summary, based on the perspective of partnership and followership, this research summarizes the current situation of leadership research, builds a cooperation model from the perspective of followership and leadership, discusses ways to improve leadership. Finally, this research proposes 5 ways to improve leadership from the perspective of cooperation and followership: (1) Improve the decisionmaking framework; (2)Conduct performance training; (3) Provide organizational guidance; (4) Flat management model; (5)Build a relationship framework.

\section{LEADERSHIP RESEARCH STATUS}

Leadership is a magical force, and people have always had a strong interest in it, and the academic field has never stopped research on leadership. Reviewing a large number of research literature on leadership, the research directions are mainly divided into two categories: one is the research on the definition and connotation of leadership; the other is the research on the leadership development.

\subsection{Definition and Connotation of Leadership}

Harold Koontz regards leadership as an influence on people, the ability to gain followers and make them willing to work hard to achieve organizational goals. James Kouzes and Barry Posner define leadership in this way in the book "Leadership". Leadership is the art of mobilizing everyone to work hard for a common vision. Professor Weiku Wu of Tsinghua University believes that leadership is a vaguely defined and broadly defined term whose core is influence and followers[1]. In 2006, the "Science and Technology Leadership Research" research group of the Chinese Academy of Sciences derives the definition of 
leadership as "Leadership is the leader attracting and influencing the leaders and stakeholders in a specific situation, and continuing to realize the group or organization The ability to target"[2]. Therefore, leadership should be defined as follows: an art that can attract and influence followers, achieve the same goal with them, and help personal growth and promote organizational improvement through a cooperative relationship with followers.

Looking at the process of understanding leadership in the West, it is found that there are two approaches to its research: individual ability and collective ability. As gods and blood are no longer the legitimate sources of leaders, people have explored the question of which characteristics make those leaders become leaders. Trait Theories gradually formed, which was a systematic theory of leadership behavior that appeared earlier in the 20th century and became popular for a while. This theory attempts to find common traits (such as personality, quality, etc.) from outstanding leaders, so as to find out the reasons for effective leadership activities. It is to reveal why leaders can become leaders and why they have leadership skills. In 1949, W. Henry pointed out that successful leaders should have twelve qualities such as strong organizational skills, strong self-confidence and quick thinking. In 1954, C.A. Gibb discovered that leaders with extraordinary capabilities tend to have seven characteristics, such as superior intelligence, handsome, and eloquent.

In the 1970s, trait leadership theory developed into Charismatic Leadership. Robert House pointed out in 1977 that charismatic leaders have three characteristics: a high degree of self-confidence, a tendency to dominate others, and a firm belief in themselves. In the 1990s, after studying the 90 most accomplished leaders in the United States, W. Bennis pointed out that charismatic leaders have four common abilities. In Burns's book Leadership, leaders are described as individuals who can motivate followers and help them better achieve organizational goals[3]. Transformational leadership is further defined as the leader by making his subordinates aware of the importance and responsibility of their tasks, inspiring and expanding the high-level needs of the subordinates, so that the subordinates' interests exceed their personal interests for the team and the organization. This also became the beginning of "transformational leadership" as an important leadership theory. Subsequently, Avolio summarized the transformational leadership behavior based on the research of Bass et al. into four aspects: idealized influence, inspirational motivation, intellectual stimulation, and personalized care. Under normal circumstances, a leader with these factors can effectively motivate employees to exceed their personal interests and make them work together for the team's goals. It is not difficult to see that the focus of attention of scholars at this time has gradually shifted from the characteristics of the leader's individual to the characteristics of the leader's organization, and how the leader handles and is led under certain circumstances. relationship. Some schools of leadership theory that emerged after the 1980s believe that any member of an organization may assume the role of a leader in a specific situation. The decentralized leadership theory schools and learning organizations that emerged in the 1990s are closer to the "collective" pole. In the 21 st century, individual leaders have become more and more limited in their ability to deal with increasingly complex and changeable challenges; along with this, heroic leadership theory in the theoretical circle has also been questioned, and the research on leadership is moving in the direction of "collective". Unl-Bien believes that individuals, groups, and organizations in the organizational system are interdependent, and sometimes the boundary between leadership and follow-up may be broken[4]. It is difficult to clarify who plays the more important role. Brown and Gioia's research shows that various organizations widely agree that organizations not only need to have competent individual leaders at all levels, but also to unite individuals to generate collective and joint leadership in the organization[5]. This is a collective ability on the overall level of the organization rather than an individual ability.

\subsection{Research on Leadership Development}

Compared with the research on the definition and connotation of leadership, more scholars are now concerned about how to improve a certain kind of leadership in an organization in a specific context, and then provide guidance for the improvement of organizational performance and the realization of organizational goals. Chinese scholars Hanhui Deng and Jinrong Li creatively proposed a leadership contingency model for front-line managers based on the enterprise life cycle theory in 2011 , and proposed corresponding leadership development methods and paths for front-line managers at different stages of the enterprise life cycle[6]. When the maturity of the enterprise increases and enters a higher stage of development, the focus of leadership of front-line managers will shift from power influence to non-power influence. As human beings enter the information society, the objects in the process of leadership - the lead, they have also undergone tremendous changes. This is the "knowledge employee" defined by Peter Drucker, and they are significantly different from those of the old industrial age in many aspects. As a current leader, not only must he exert influence on knowledge workers to accomplish the goals of the enterprise, but he must also learn how to adapt to the new characteristics and changes of knowledge workers. The leader's ability to influence and adapt to knowledge-based employees is an important manifestation of their leadership, and this kind of benign interaction between the leader and the led can further enhance their leadership. Guoqing Huo conducted an empirical study on the leadership of Chinese CEOs based on the characteristics of knowledge employees, and found that CEOs who are good at shaping multiculturalism, attracting and influencing employees, and empowering management generally produce higher corporate performance, and therefore also have stronger leadership[7] 
Regarding leadership development, the highest citation rates in the relevant western research literature are the views of the CCL and the views of scholar Day. CCL believes that leader development is an aspect of leadership development. Cultivating leaders with higher potential and increasing the reserve of reserve leaders can only enhance the leadership ability of the organization to a certain extent. Organizations must not only develop individual leadership capabilities, but also collective leadership capabilities. Strengthening the close ties between individuals and between teams within the organization can enable members of the organization to cross organizational boundaries and work more efficiently in an open and inclusive way. Basically, consistent with CCL's point of view, Day calls the development of personal leadership as leader development. He believes that leader development is the improvement of human capital, and leadership development is the increase of social capital, based on the network relationship between individuals. Close cooperation and strengthen the exchange of resources. Later, Day regarded leadership development as a multilevel process: the first level is the personal development of the leader; the second level involves the relationship between the leader and followers, peers and bosses; the third level is the relationship To organizational culture. Day's argument has been widely recognized by related researchers, and some scholars have expanded on this basis. For example, in 2004 O'Connor et al. proposed that the development of leadership depends on the development of human capital, social capital and organizational capital. In 2007, Bartol and others believed that the development of leadership involves the development of human capital, social capital and system capital. It is not difficult to see that the views of these two scholars are actually consistent with Day's exposition.

\section{LEADERSHIP RESEARCH ANALYSIS FROM MULTIPLE PERSPECTIVES}

\subsection{The Background of the Rise of Followership Research}

As a leader in the study of following power, Barbara Kellerman pointed out in her subversive leadership book "Following Power": "In the 21st century, the new era is destined to be different from the past. Followers are more in the past, leaders have more power to speak, and leaders no longer give orders to everything." The reason why Barbara Kellerman made such a judgment is mainly because he has insight into the changes that are taking place in the world we live in. This change Makes the research on the following power inevitable. First, under the baptism of the post-era wave, the overall "center" and "authority" are gradually deconstructed, traditional values are replaced by new and diverse values, and the previous unidirectional leadership discourse system is gradually disintegrated and possessed by leaders In addition, the advent of the era of big data has accelerated the speed of knowledge updates, and the channels for obtaining information are more diversified. Leaders cannot control everything, and more and more seek help from the leaders. Finally, the drawbacks of the bureaucracy are becoming increasingly apparent, the hierarchical system of organizations is gradually disintegrating, and the trend of flattening is about to emerge. These factors have transformed the relationship between the traditional leader and the led from the superior to the leader and the follower. In this context Next, the Western leadership academic circles began to study the follow-up force [8]

Regarding the domestic research on followership in CNKI, from July 2008 to April 2021, there were 72 documents directly related to "followership " in the core journals of Peking University and CSSCI source journals. Among them, there are 34 articles with the theme of "implicit followership", 22 articles with the theme of "positive followership", 5 articles with the theme of "team followership", and 11 other related studies. There are 36 master and doctoral dissertations related to followership, including 2 doctoral dissertations and 34 master's dissertations

\subsection{The Definition of Followership}

At present, there are mainly five definitions of following power that are popular in academic circles at home and abroad [9]. One is to regard following power as the courage of followers. For example, Chaleff's definition is: Following power is the courage of followers to assume responsibility, courage to serve, courage to challenge, courage to change, and courage to leave. The second is to define following power as the positive willingness of followers. For example, Joshua Frye and David Butts pointed out that following power can be defined as a way of accomplishing team tasks through cooperation, showing a high degree of team spirit and establishing a kind of cooperation in the team. Positive willingness. The third is to define following power as a kind of superior-subordinate relationship. As Kellerman pointed out, following power is the relationship between superior and superior and the behavioral response of subordinate to superior. The fourth is to define the following power as the following ability of the follower. As Bjugstad pointed out, following power is the ability of the follower to effectively implement the leader's instructions and support the leader's work. Its goal is to maximize the organization's goals. The fifth is to regard following power as a behavior of followers under the direction of people. For example, Jehn and Bezrukova pointed out that following power is a kind of peopleoriented behavior. This behavior establishes the relationship between the leader and the follower. This provides an environment for leaders and followers to lock in a common goal. 


\subsection{Construction of Partnership Model from the Perspective of Followership and Leadership}

The formation of a partnership requires leaders and followers. The relationship between them should be equal, unified, dynamic and harmonious, but not completely the same. The leader sets the framework in the partnership to create the best conditions for success and best performance. Followers create within the framework established by the leader to maximize their own value. Excellent leadership can help people become better. It creates a working environment, attracts and motivates workplace partners, builds relationships, breaks barriers to progress, and creates conditions for success.

In the process of cooperation, people in different roles in the organization should be made aware that everyone is an equal devotee with the same value. In modern organizations, leadership is dynamic. Leadership should be regarded as the function of every employee, and leadership is also a skill that every employee should possess. Therefore, the development of leadership is not only what senior managers should do. Every employee should also devote himself to the development process of leadership. Through the design of appropriate organizational structure and the allocation of appropriate jobs, it is necessary for all levels talent provides opportunities.

\section{IMPROVE LEADERSHIP FROM THE PERSPECTIVE OF PARTNERSHIP AND FOLLOWERSHIP}

First, improve the decision-making framework and create a working environment and process that can optimize the quality of collaboration and decision-making. Decisionmaking is an important responsibility of leaders. To improve the ability of scientific decision-making, leaders not only need to master the principles of scientific decision-making and understand the scientific decisionmaking procedures, but more importantly, cultivate the ability to foresight, foresee the development of things, and improve the ability of scientific forecasting.

Second, conduct performance training to ensure the same goals and create a positive working atmosphere. Regular corporate training, employees and executives learn together, because executives can have a good discussion in the process of learning with employees, and even major issues that the company is currently facing. At the same time, the process of communication can enable executives and employees to communicate with each other. The thinking between the two is more unified.

Third, provide organizational guidance to help guide other employees on how to maximize their own value within the organization, and cultivate employee following and leadership. To carry out systematic leadership education within the organization, the company should regularly select a group of potential employees to the corresponding colleges and universities for systematic leadership education, and then use these employees who have received systematic leadership education as the backbone to establish the internal leadership of the organization The education system, including the setting of education courses and learning, and the integration of leadership education into the performance appraisal of employees, truly makes leadership education a part of employees' work.

Fourth, the flat management model allows team members to understand the organization's strategic positioning, and integrate resources globally and dynamically. Organizational structure has a great relationship with the improvement of leadership. If an organization wants to improve its own leadership, it should flatten the organizational structure and strengthen the establishment of a decentralized structure, especially under the support of the organization's overall leadership improvement concept. The flattened organizational structure and decentralization will enable employees and some managers to have greater flexibility. They can choose as appropriate methods as possible to enhance their own influence, and at the same time, they can communicate with their superiors to make the leadership training plan more effective implementation [10].

Fifth, build a relationship framework to create a comfortable, professional and fair environment for each team member. Make employees feel respect and equality, and enable them to combine the vision of the organization with their own values, and even participate in the formulation of the vision of the organization, so as to achieve the consistency of the vision of the organization with their own goals.

\section{CONCLUSION}

The research on leadership has always been attached great importance by the management academia, and the research on followership is not a new area, but the management academia has only begun to pay attention to it in recent years. This is due to the importance of a series of humanization and individualization in current management practices. As an emerging research field, the basic issues of followership research are still relatively vague and need to be discussed in depth. Based on this, this research first sorts out the historical context of leadership and leadership development research, and analyzes the connotation and definition of followership. Furthermore, this research constructs a cooperation model from the perspective of followership and leadership, which provides a thinking angle for the formation of the cooperative relationship between leaders and followers. Finally, it provides suggestions for improving leadership from the perspective of cooperation and followership from five aspects. In the current management background of increasing individual value and autonomy of employees, the development of followership research helps to respond to a series of new problems in management practices regarding individual changes and organizational development. 


\section{REFERENCES}

[1] Weiku Wu. Study on the Harmony Building Based upon Three-layered Leadership[J]. Journal of China University of Geosciences(Social Sciences

Edition), 2010,10(01):99-103+109.

DOI:10.16493/j.cnki.42-1627/c.2010.01.019

[2]"Science and Technology Leadership Research" Research Group of the Chinese Academy of Sciences, Jianming Miao, Guoqing Huo. Research on the Five Forces Model of Leadership[J]. Leadership Science,2006(09):20-23.DOI:CNKI:SUN:LDKI.0.200609-011.

[3] Burns, J. M. Leadership. New York: Harper Row, 1978.

[4] Uhl-Bien, M., Riggio, R. E., Lowe, K. B., Carsten, M. K. Followership Theory: A Review and Research Agenda. The Leadership Quarterly, 2014, 25(1): 83104. DOI: 10.1016/j.leaqua.2013.11.007

[5] Tian Shao. Summary of Leadership Research[J]. Journal of Hebei University of Engineering(Social Science Edition),2014,31(01):24-25+38. DOI:

CNKI:SUN:HJZK.0.2014-01-007.
[6] Hanhui Deng, Jinrong Li. Leadership Development of Frontline Managers Based on Enterprise Life Cycle[J]. Human Resources Development of China,2011(11):72-75. DOI:10.16471/j.cnki.112822/c.2011.11.022

[7] Guoqing Huo, Hui Zhang, Jianping Meng. An Empirical Study of CEOs' Leadership Based on the Characteristics of Knowledge Workers in China [J]. Science \& Technology Progress and Policy,2010,27(04):138-141.

DOI:CNKI:SUN:KJJB.0.2010-04-036.

[8] Hui Jin. Leadership should pay attention to the study of following power[J]. Inner Mongolia Coal

Economy,2017(11):20-21.

DOI:10.13487/j.cnki.imce. 010048

[9] Yuankun Cao, Sheng Xu. Thoughts on Several Viewpoints in the Theory of Follower[J].Jiangxi Social Sciences,2013,33(02):203-206.

DOI:CNKI:SUN:JXSH.0.2013-02-041.

[10] Jianfeng Peng. Cultivating leadership and leadership team[J]. China Power Enterprise Management,2005(05):32-33. DOI: CNKI:SUN:ZGDQ.0.2005-05-014. 